\title{
Gender differences among dentistry conference speakers in Brazil
}

\author{
Diferenças de gênero entre palestrantes de congressos odontológicos \\ no Brasil
}

Leandro Brambilla Martorel|1,2, Ana Luiza Mustafe Silva², Cláudio Rodrigues Leles², Brunno

Santos de Freitas Silva², Cristina Vianna Moreira dos Santos ${ }^{\mathbf{3}}$, Mirelle Finkler $\mathbf{4}$

DOI: 10.1590/0103-11042021E106

\begin{abstract}
This study aimed to evaluate possible gender differences among the invited speakers of Brazilian dentistry meetings. The selected meetings $(n=15)$ were held in different states distributed among the five Brazilian regions. The conference programs were manually reviewed, and a database was constructed. Data analysis was performed using descriptive statistics, chi-square and Mann-Whitney tests. A total of 1,195 speakers was identified, $19.7 \%(n=235)$ of which were women. The results of this study provide an overview of the trends of gender disparity in dentistry conferences in Brazil. These findings suggest disseminated gender-discriminatory practices in the promotion of women participation as speakers in such events. This requires more effective approaches to promote gender balance among conference organizing committees and encourage greater visibility and promotion of equity and diversity policies in dental professional societies to ensure more equitable conference programs.
\end{abstract}

KEYWORDS Dentistry. Sexism. Gender inequality. Gender and health. Feminism.

1 Universidade Evangélica de Goiás (UniEVANGÉLICA) Anápolis (GO), Brasil. Ibmartorell@gmail.com

2 Universidade Federal de Goiás (UFG) - Goiânia (GO), Brasil.

3 Universidade Federal do Tocantins (UFT) Miracema (GO), Brasil.

4 Universidade Federal de Santa Catarina (UFSC) -

Florianópolis (SC), Brasil.

RESUMO Este estudo objetivou avaliar possíveis disparidades de gênero entre palestrantes de congressos de odontologia. Os congressos selecionados $(n=15)$ aconteceram em diferentes estados, distribuídos entre as cinco regiões do País. A programação dos congressos foi avaliada, e um banco de dados foi construído. Os dados foram analisados por estatística descritiva (testes qui-quadrado e Mann-Whitney). Foram identificados 1.195 palestrantes, dos quais 19,7\% (n=235) eram mulheres. Os resultados deste estudo fornecem uma visão geral das tendências de disparidade de gênero em conferências odontológicas no Brasil. Sugerem disseminação de prática discriminatória na participação de mulheres como palestrantes nesses eventos. São necessárias abordagens mais eficazes para promover o equilíbrio de gênero entre os comitês organizadores dos congressos, encorajando e promovendo políticas de equidade e diversidade, ampliando a participação e o protagonismo das mulheres nesses eventos.

PALAVRAS-CHAVE Odontologia. Sexismo. Iniquidade de gênero. Gênero e saúde. Feminismo. 


\section{Introduction}

The trend in student access to higher education in Brazil has changed over the last decades, with greater access of underprivileged students and a significant growth in the number of women students. They correspond to $53.9 \%$ of the total number of students, $55.6 \%$ of the total enrollment of undergraduate courses, and $59.9 \%$ of the total number of college graduates ${ }^{\mathbf{1}}$. Both the rise in the level of education and broader access of Brazilian women to education were crucial factors for the entry and establishment of women in the job market ${ }^{2}$.

In Dentistry, data from 2007 showed a tendency of increase in the number of women dentists: they accounted for $64.3 \%$ of the number of college students enrolled, and $65.8 \%$ of the number of graduating students in Brazil ${ }^{3}$. Data from 2020 indicate that the number of women enrolled in dentistry courses increased its representativeness to $71.5 \%{ }^{4}$. In addition, since the 1990s, the number of registered women dentists in Brazil has surpassed men ${ }^{3}$, and recent data show that they are the majority among specialized dentists - 68,958 (55.7\%) women opposed to 54,763 (44.3\%) men ${ }^{5}$.

Despite the changes in undergraduate and graduate courses, gender equity in the job market remains disproportional in several professional areas in different countries. Data from the United States show that health professionals have marked differences in access to high education and salary between men and women ${ }^{6}$. This also happens in North American dentistry, where there is a clear disparity in favor of men in leadership positions, and the higher the position, the greater the gender imbalance regarding salary and career advancement 7,8 .

Although women professionals exist in large numbers, sociocultural differences are still perceived, and these women remain underrepresented in specific, more socially valued areas $^{9}$. Studies have investigated gender trends related to dentistry professionals and reported unfavorable situations faced by women, such as their clear disadvantage compared to men in leadership positions $\mathbf{8}^{\mathbf{8}}$, lower academic degrees and less specialization ${ }^{9}$, lower respect shown by students in academic environments ${ }^{\mathbf{1 0}}$, and lower representativeness on editorial boards of scientific journals ${ }^{\mathbf{1 1}}$.

Underrepresentation of female professionals was also related to the proportion of speakers of scientific meetings, as observed in several health fields ${ }^{\mathbf{1 2}, \mathbf{1 3}}$. However, there are no specific studies regarding the number of women lecturers in dental-related events. Therefore, the objective of this study was to examine possible gender disparities in guest speakers at Brazilian dentistry conferences. In Brazil, studies addressing gender disparities in dentistry are scarce.

\section{Material and methods}

The sample consisted of dentistry conferences held between 2015 and 2017. A two-year interval corresponds to the usual frequency of scientific events in dentistry, it also corresponds to the beginning and end of the graduation thesis that originated this research. The selected events covered all five Brazilian regions (Midwest, Northeast, North, Southeast, and South). In the sample, there were at least two conferences from each region, only one per state. As additional criteria, the events had to have been organized by recognized educational institutions in the field (such as universities and the Brazilian Dental Association) and include several fields and specialties of dentistry (specific specialty dental conferences were not considered to avoid possible bias). Internet search engines were used for data collection (Google search, Bing, and Yahoo).

Based on the results, further information was collected from websites available online, which included the complete program of each conference. As for the conferences which did not have their programs available online, direct contact was made with organizers to request 
them. Any conference for which a complete program could not be obtained was excluded from the sample. If the search yielded more than one conference in the same state, only the most relevant one (greater number of lectures and speakers) was considered.

The following data were extracted from the program of each conference: duration (in minutes), main topics (to categorize the area of dentistry), number of speakers and name of the speaker. Regarding lectures with more than one speaker, each speaker was considered individually in the sum. Events parallel to the congress and not directed at general dentists were not considered. No data were collected regarding the nationality, birthplace, or academic education of the speakers.

In opposition to the concept of sex that categorizes people based on biological attributes, was used a gender classification based on constructed roles, behaviours, expressions and identities of girls, women, boys, men, and gender diverse people. A binary gender categorization (woman/ man) was adopted to aid in performing the analysis ${ }^{\mathbf{1 4}}$, given the complexity of the gender gradient and its sociocultural influence. All the speakers were ranked based on the usual gender name chosen to identify themselves in the event program. In Brazil, unisex names are not usual, and it makes this kind of evaluation possible. For names that might raise doubts (for example: international speakers) the speaker was searched individually to determine the correspondent gender.

Data analysis was performed using descriptive statistics, including the frequencies and percentages of the variables analyzed. The chi-square and Mann-Whitney tests were used to compare the frequencies of the distribution by gender and the variables analyzed. The significance level adopted was $5 \%$. IBM-SPSS 24.0 software was used to construct and statistically analyze the database.

\section{Results}

Programs from fifteen conferences covering all five Brazilian regions were obtained, specifically, two from the Midwest, two from the North, five from the Northeast, three from the Southeast, and three from the South. The total number of speakers ( $\mathrm{n}=$ $1,195)$ in the selected events was distributed according to the respective year, as follows: $175(14.6 \%)$ in $2015,189(15.8 \% \%)$ in 2016 , and $831(69.5 \%)$ in 2017.

The speakers selected from the programs were distributed as follows: of the total 1,195 speakers, 960 (80.3\%) were men and 235 (19.7\%) were women. The number of speakers of each gender, according to the year of the event, is shown in graph 1 . There was no significant difference in the proportion of women to men speakers based on the year of the event $(\mathrm{p}=0.394)$.

Likewise, graphs 2 and 3 show the distribution by gender, according to the region and the lecture topics, respectively. The grouping of states by region showed that the proportion of women to men speakers ranged between $14.3 \%$ in the Midwest and 26.2\% in the Northeast ( $p=0.006)$. Regarding the representativeness of women according to the lecture topic, there was a significant difference between the genders $(p<0.001)$. The lowest proportion of women to men occurred in the fields of implants (4\%) and oral surgery (7.2\%), whereas the highest was seen in the fields of public health (64.7\%), stomatology (58.3\%) and pediatric dentistry (52.2\%).

The lectures taken from the programs had up to eight speakers, and lasted from at least fifteen up to 300 minutes. The duration of the lectures was adjusted according to the number of speakers, by dividing the total duration by the number of lecturers. There was no significant difference $(\mathrm{p}=0.187)$ in the duration of lectures given by men (mean $=77.9$, standard deviation $=42.3)$ compared to those given by women ( mean $=75.9$, standard deviation $=45.4)$. 
Graph 1. Number of speakers of each gender, according to the year of the event

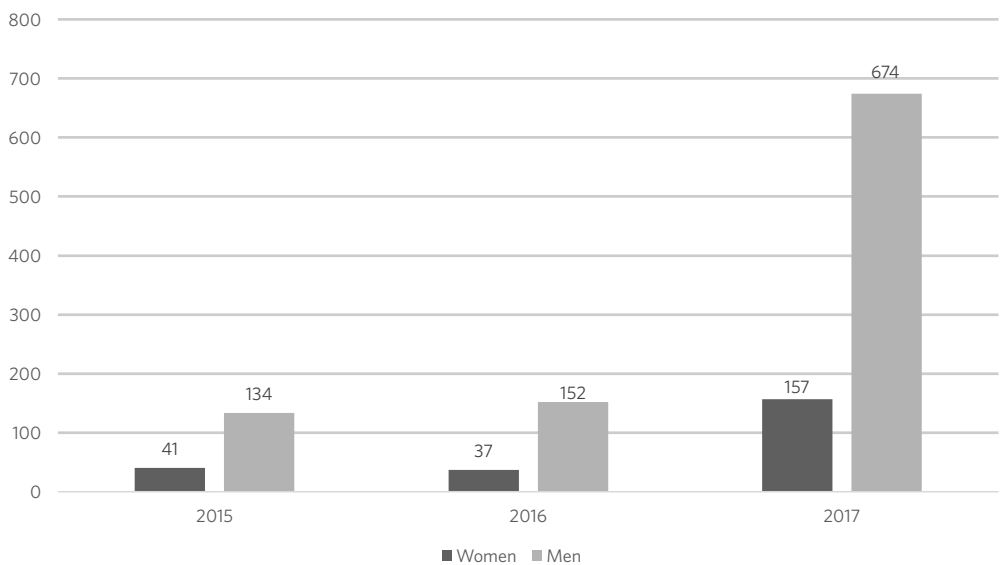

Source: Self elaboration.

Graph 2. Distribution of speakers by gender and region

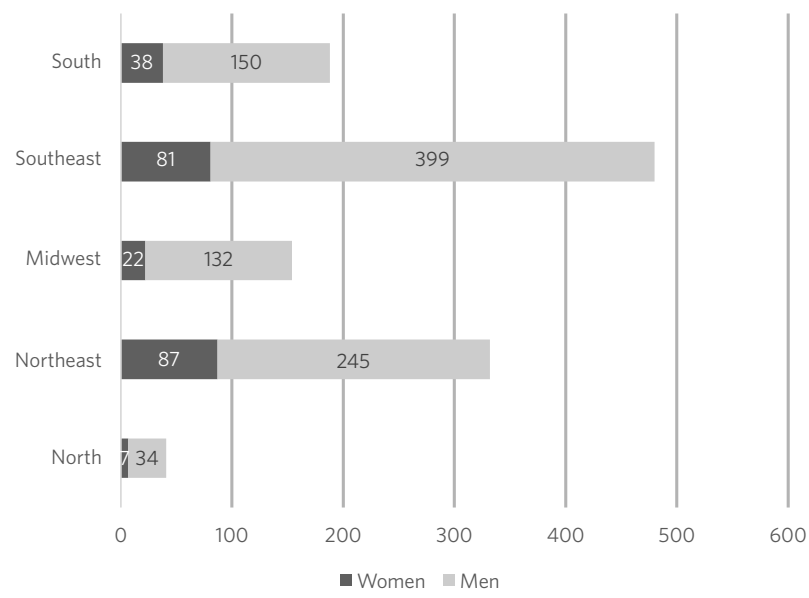

Source: Self elaboration.

Graph 3. Distribution of speakers by gender and themes of the lectures
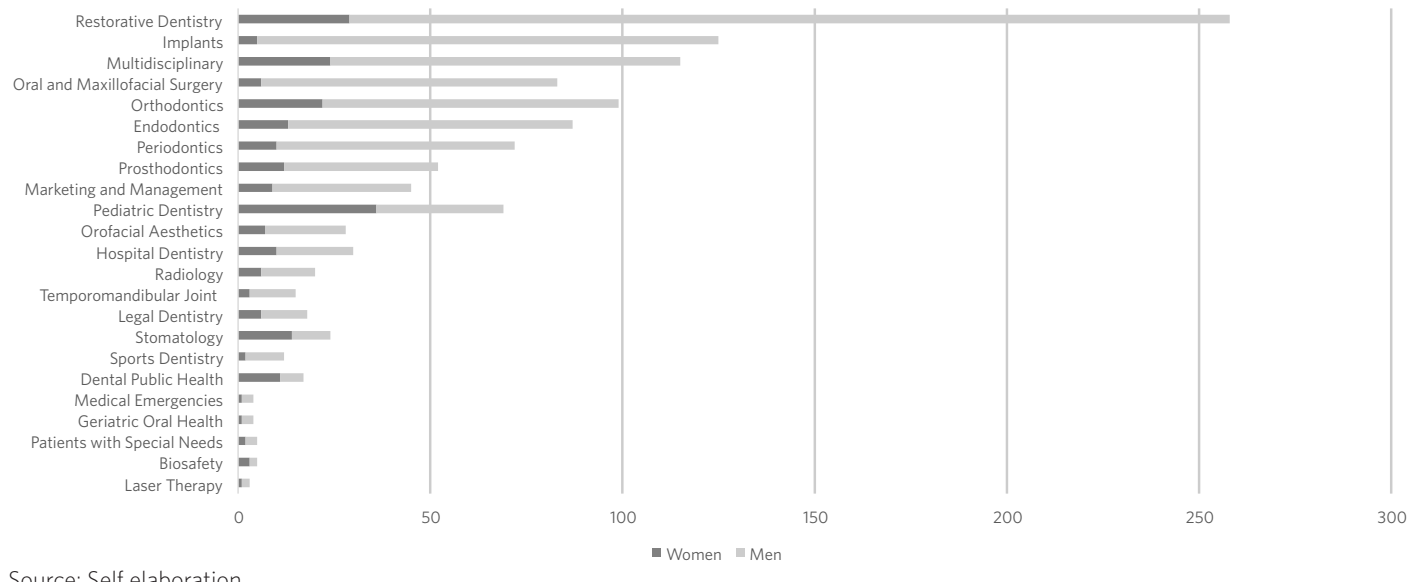

Source: Self elaboration. 


\section{Discussion}

An analysis of women participation in a professional field or area of expertise transcends the simple engagement in a gender discussion. When considered as an instrument of analysis, gender deals with the existing power relations between men and women and upsets the processes of naturalization of their social roles. Thus, it is extremely important to analyze the processes related to the occupation of spaces by women, to engage in eliminating discrimination, and to promote sustainable social and economic development ${ }^{15}$.

The outcome denounces the inequality between genders, which endures in the realm of institutional spaces, particularly in political and scientific fields. The number of women speakers at dental conferences was evaluated using a quantifiable method to assess the representativeness and visibility of women; the results confirm women underrepresentation. Similar results have been found in other healthrelated areas; for example, a fewer number of women (29.9\%) versus men (70.1\%) speakers have been reported in conferences on medical emergencies ${ }^{\mathbf{1 6}}$. In addition, women tend to give their lectures for fewer hours at evolutionary biology conferences, even though the ratio of women to men attending the conference is practically $1: 1^{17}$.

This study showed a similar trend regarding presentation time; it was found that male speakers gave longer lectures, even though there was no statistic difference observed. However, unlike other fields of knowledge, Brazilian dentistry indicators record women as the majority in undergraduate courses and in the job market of most states ${ }^{3}$, further underscoring the gender disparity. Data from the Brazilian Federal Dentistry Council of 2010 indicate that women dentists are the majority in all regions of the country, totaling more than half of its members in all regions, in that the Northeast and the North have the highest percentage of women members, respectively. Unfortunately, current data has not yet been made available, however, it is more likely that today the proportion of women is even higher.

The reasons for this phenomenon are extensive, complex, and diverse. The behavioral and cultural differences between boys/men and girls/women can be identified even at young ages. Girls tend to work more at domestic tasks than their brothers ${ }^{\mathbf{1 8}}$. Even considering a greater workload taken on by a woman than a man while attending college, her educational indicators are superior to his, a fact observed since the $1950 \mathrm{~s}^{19}$. Regarding Brazilian higher education, more women than men apply to college and take better advantage of their education ${ }^{19}$. Enrollment in college is based on classification, whereby applicants are admitted up to the total number of vacancies. This system was established decades ago and remains in place today, with only minor changes. Some courses require writing skills and other specific abilities, and there are several different types of tests for which different scores are given, based on the career being pursued ${ }^{\mathbf{2 0}}$. Access to higher education in Brazil reflects sociocultural inequalities, but there is no gender disparity statistically speaking ${ }^{\mathbf{1 4}}$.

Although course admissions are apparently gender-equal, the differences begin to appear once college starts and continue through the following years. A study carried out in the United States of America found that women dentistry students feel significantly less selfconfident. They may observe inadequate treatment dispensed to women faculty members, may perceive gender differentiation in how the faculty communicates with them or the clinical staff treats them, and are prone to experiencing undesirable sexual advances or behavior toward themselves or their women colleagues ${ }^{10}$. In addition, gender biases may hamper a woman's opportunities; men candidates for academic research positions in science are likely to be judged as significantly more competent and engaging than women candidates with identical qualifications ${ }^{21}$. Although such evidence comes from different socio-cultural realities which may represent 
an analysis bias, it must also be considered that gender inequalities have, too, intercultural roots.

Education plays a specific cultural and ideological role and contributes to maintaining and reproducing social status by preserving the power and privileges of society. Even in undergraduate courses, this process may be noticed as the so-called hidden curriculum, in which the student incorporates implicit standards, values, and ideologies into their curriculum. This overall perception engenders values ultimately imputed to professional practices, interests, and prestige related to the particular specialties and power involved in the dynamics of interpersonal relations ${ }^{22}$. For example, there is a preference for pursuing technical subjects, and for valuing clinical and surgical work, to the detriment of areas which become devalued, such as public health ${ }^{22}$. Professional success models may be indirectly related to gender issues; consider that women are the majority in public dental health (66\%), whereas they have only few representatives in careers such as surgery $(20 \%)^{3}$.

Women and men also have clearly different expectations regarding their specialty. Considerably more women plan careers in general dental practice and pediatric dentistry, whereas more men envisage pursuing a career in oral and maxillofacial surgery ${ }^{\mathbf{2 3}}$. In Brazil, women are the majority in specialties such as pediatric dentistry (85\%), public health (66\%), restorative dentistry (62\%), and endodontics (57\%), whereas men predominantly pursue specialties such as surgery (20\%), implants (22\%), prostheses (40\%), and radiology (40\%)

In this study, women were found to be a minority in most specialties. There were only four areas that had a higher number of female than male professionals: biosafety, stomatology, pediatric dentistry, and public health.

Gender segregation becomes evident when we consider its horizontal and vertical implications. It can be considered horizontal when observing the differences in the choice of specialties, and vertical when considering that the higher positions registered at the Brazilian Academy of Dentistry are filled mainly by dentists of the male gender ${ }^{9}$. The underrepresentation of women on the editorial boards of dental journals is also perceived ${ }^{1}$. The sum of these conditions contributes to women's lack of visibility, which ultimately leads to a lack of role models for young dentists, and which perpetuates segregation.

Although the presence of women may be considered a factor of inspiration, it has been suggested that they may also generate more opportunities for other women. Studies show that the presence of women in organizing committees is directly correlated with the number of women speakers at conferences $\mathbf{1 2}^{\mathbf{2} 24}$. In addition, a positive correlation was established between the presence of women in the editorial leadership of a newspaper and the percentage of women who serve as members of its advisory board"1.

In a qualitative survey conducted in Canada, the women interviewed worked fewer hours due to the challenges involved in maintaining their profession and taking care of their children at the same time, as well as them valuing family happiness over their work status ${ }^{25}$.

The discrepancy of perceived success between men and women in science is often attributed to the different lifestyle choices that men and women make, especially regarding their decision of having or not having children. Because women's social orientation is to be primarily responsible for their family, their household, and their family's health, the job of caring for a family still falls disproportionately on women; this could explain why women quit their careers at advanced stages. Compared to paternity, motherhood involves not only more total time commitment, but also more multitasking, more physical work, a tighter schedule, more alone-time with children, and greater responsibility in managing general care. These gender differences in the extent and nature of caregiving apply even when women work full time ${ }^{26}$. However, this should be considered only part of the issue; in general, 
there is evidence of equal levels of productivity between mothers and non-mothers in peerreviewed publications ${ }^{\mathbf{1 2}}$.

It is common for event organizers to be specifically responsible for inviting the speakers. There is a great chance that gender bias may be at play, and that men will receive more invitations ${ }^{12}$. Nevertheless, when women are invited, a number of factors may make it difficult for them to accept the invitation, such as time availability and expenses related to transportation and accommodations ${ }^{\mathbf{1 2}}$. Not all conferences can offer financial aid to the lecturers, and there is the additional disadvantage that female professionals tend to earn less than male professionals, a tendency observed not only in dentistry ${ }^{7}$, but also in other health-related areas ${ }^{6}$. There is evidence that a woman's burden of commitments makes her more likely to refuse invitations to speak ${ }^{\mathbf{1 3}}$; this is yet another factor that results in reduced visibility for women scientists ${ }^{15}$.

Although the data collection period is a limitation of this study, the evaluation of conferences dating from 2015 to 2017 shows the current trends of representativeness and visibility of women in a quantitative perspective. The difficulty of advancement and visibility for women is a phenomenon known as the glass ceiling. This is an invisible barrier that blocks the advancement of women to prominent positions in the organizational structures of the workplace, 27. It is a structural problem and requires action and effort from many segments before it can be mitigated. Essentially, the barriers to the advancement of women in several spheres must be brought down, especially in schools, colleges, postgraduate programs, and the job market, and greater visibility must be promoted.

The time engaged in public speaking is an important indicator of how gender parity should be encouraged in the academic context. This study pointed to a more extensive overall use of time by men in all conferences. Guaranteeing an allotted amount of time to women speakers does not mean only dividing the time among the lecturers of an event, but also valuing the discussion promoted by them, thus establishing fairness among colleagues. This affirmative action of time management aims to displace men from their historically assured position - one of the privileges in the use of speech and circulation through public spaces. The upshot would give greater visibility to the achievements made by women. In the academic sphere, professors and mentors should ensure opportunities and spaces for women to realize their full potential. Some interesting, alternative avenues to develop this potential are the inclusion of disciplines that enhance leadership skills, the raising of student awareness, and the providing of teacher training.

Regarding conferences, some strategies can be recommended to increase the participation of women, so that the ultimately desired and needed gender balance can be achieved. Possible avenues include obtaining data on gender inequalities of conferences and presenting the findings to the event committee. The basic intent is to raise awareness, increase the number of women responsible for selecting the lecturers to be given at a certain conference (ultimately associated with a greater number of women speakers), and give direct instructions to the committee to reduce gender differences ${ }^{28}$. In the process of choosing speakers from the abstracts submitted, a possible criterion is to make the speaker selection committee blind to the selection process by not specifying the author's name.

This study provides an interesting overview of the current trends of gender parity related to dentistry symposia in Brazil. However, one of its limitations was the difficulty to obtain some of the schedules of the conferences, once they are taken out from the online platforms after the end of the event. Also, each Brazilian region presents different sociocultural and demographic characteristics, which reflected in the distribution pattern of the congresses. 
The congresses held in the North region are scarce, in contrast to the abundance of congresses in the Southeast region. This situation makes selection difficult to comprehensively cover all regions. Another difficulty had already been perceived in a previous study, as the speaking time was determined as the schedule time, and not the real lecture recording ${ }^{18}$. Furthermore, providing a quantifiable approach to evaluate gender issues is a challenge. More studies are necessary to improve the methodology and provide awareness regarding gender equality, especially in South America.

By analyzing the participation of women as lecturers in dentistry conferences, this study has sought to discuss the gender issue that arises from the naturalization of social and cultural roles for the genders, through educational and socialization processes. If this issue is not problematized, it will tend to crystallize by undermining the growth potential of the profession, and the visibility of the work produced by women. Gender parity is needed as a strategy to allow the empowerment of women in the institutional realms of power. The ultimate goal is to seek equality for women and to build stronger democratic and fair relations in the professional field.

The initial recognition of disparity, and the subsequent adoption of measures to achieve gender balance, are vital. These changes may enable individuals on both sides of the gender line to develop to their full potential and promote the advancement of dentistry. The dental profession can benefit greatly from the growth and visibility of women.

\section{Conclusions}

This study provides an overview of the current trends of gender disparity related to dental conferences in Brazil. Differences were found between the number of men and women speakers, in that the proportion of men speakers was greater. These data contrast with the feminization of Brazilian dentistry, showing that possibly female dentists do not have as much visibility in congress scenarios as male dentists. Such finding corroborates the need for interventions to change reality and promote greater visibility and growth potential for women dentists. More studies are necessary to properly assess gender issues in dentistry and advance towards gender equality. It is essential that the responsible institutions disclose information about the number of registered dentists and dentistry professors in Brazil by gender. Thus, more accurate analyses can be performed.

\section{Collaborators}

Martorell LB (0000-0003-2343-754X)*, Silva ALM (0000-0002-5490-3737)* and Leles CR (0000-0002-1437-2871)* have contributed to the design and planning of the research, for analysis and interpretation data, for drafting and critical review of the content and approval of the final version of the manuscript. Silva BSF (0000-00021437-2871)*, Santos CVM (0000-0001-79529588)* and Finkler M (0000-0001-5764-9183)* have contributed to the preparation of the critical review of the content and approval of the final version of the manuscript. 


\section{References}

1. Instituto Nacional de Estudos e Pesquisas Educacionais Anísio Teixeira. Censo da Educação Superior 2016. Brasília, DF: Ministério da Educação; 2017. [accessed on 15 Oct 2017]. Available on: http://download.inep.gov.br/educacao_superior/censo_superior/ apresentacao/2016/apresentacao_censo_educacao_ superior.pdf.

2. Quirino R. Trabalho da mulher no Brasil nos últimos 40 anos. Rev. Tecnol. Soc. 2012; 8(15):90-102.

3. Morita MC, Haddad AE, Araújo ME. Perfil atual e tendências do cirurgião-dentista brasileiro. Maringá: Dental Press; 2010.

4. Brasil. Instituto Nacional de Estudos e Pesquisas Educacionais Anísio Teixeira. Resumo técnico do Censo da Educação Superior 2019. Brasília, DF: Instituto Nacional de Estudos e Pesquisas Educacionais Anísio Teixeira; 2021.

5. Conselho Federal de Odontologia. Sistema de Cadastro - Rotina SISGER23. [accessed on 2021 May 20]. Available on: https://website.cfo.org.br/estatisticas/ quantidade-geral-de-cirurgioes-dentistas-especialistas/

6. Desai T, Ali S, Fang X, et al. Equal work for unequal pay: the gender reimbursement gap for healthcare providers in the United States. Postgrad Med J. 2016; (92):571-5.

7. Brown LJ, Lazar V. Differences in net incomes of male and female owner general practitioners. J Am Dent Assoc. 1998; 129(3):373-8.

8. Whelton H, Wardman MJ. The Landscape for Women Leaders in Dental Education, Research, and Practice. J Dent Educ. 2015; 79(supl5):S7-12.

9. Pallavi SK, Rajkumar GC. Professional practice among woman dentist. J Int Soc Prev Community Dent. 2011; 1(1):14-9.
10. Tiwana KK, Kutcher MJ, Phillips C, et al. Gender Issues in Clinical Dental Education. J Dent Educ. 2014; 78(3):401-445.

11. Ioannidou E, Rosania A. Under-Representation of Women on Dental Journal Editorial Boards. PLoS ONE. 2015; 10(1):e0116630.

12. Sardelis S, Drew JA. Not "Pulling up the Ladder": Women Who Organize Conference Symposia Provide Greater Opportunities for Women to Speak at Conservation Conferences. PLoS ONE. 2016; 11(7):e0160015.

13. Schroeder J, Dugdale HL, Radersma R, et al. Fewer invited talks by women in evolutionary biology symposia. J. Evolut. Biology. 2013; (26):2063-9.

14. McCowan T. Expansion without equity: An analysis of current policy on access to higher education in Brazil. Higher Educ. 2007; 53(5):579-98.

15. United Nations Depelopment Programme. Support to the Implementation of the Sustainable Development Goals. [accessed on 2017 Nov 7]. Available on: http://www.undp.org/content/undp/en/home/librarypage/sustainable-development-goals/undp-support-to-the-implementation-of-the-2030-agenda/.

16. Carley S, Carden R, Riley R, et al. Are there too few women presenting at emergency medicine conferences? Emerg Med J. 2016; (33):681-3.

17. Jones TM, Fanson KV, Lanfear R, et al. Gender differences in conference presentations: a consequence of self-selection? PeerJ. 2014; (2):e627.

18. Plan International Brasil. Por ser menina no Brasil: crescendo entre direitos e violências. São Paulo: Plan International Brasil; 2015. [accessed on 2017 Nov 10]. Available on: http://primeirainfancia.org.br/wp-content/uploads/2015/03/1-por_ser_menina_resumoexecutivo2014.pdf. 
19. Rosemberg F, Andrade LF. Ação afirmativa no ensino superior brasileiro: a tensão entre raça/etnia e gênero. Cadernos Pagu. 2008; (31):419-437.

20. Borges JLG, Carnielli BL. Educação e estratificação social no acesso à universidade pública. Cadernos de Pesquisa. 2005; 35(124):113-139.

21. Moss-Racusin CA, Dovidiob JF, Brescollc VL, et al. Science faculty's subtle gender biases favor male students. PNAS. 2012; 109(41):16474-16479.

22. Finkler M, Caetano JC, Ramos FRS. Modelos, mercado e poder: elementos do currículo oculto que se revelam na formação em odontologia. Trab. educ. saúde. 2014; 12(2):343-361.

23. Dhima M, Petropoulos VC, Han RK, et al. Dental Students' Perceptions of Dental Specialties and Factors Influencing Specialty and Career Choices. J Dent Educ. 2012; 76(5): 562-73.

24. Casadevall A, Handelsman J. The presence of female conveners correlates with a higher proportion of female speakers at scientific symposia. mBio. 2014; 5(1):e00846-13.
25. Rajeh M, Hovey R, Esfandiari S. An Inquiry into Female Dentists' Professional Lives and Concerns. Open J Soc Sci. 2014; 2(8):121-9.

26. Craig L. Does father care mean fathers share? A comparison of how mothers and fathers in intact families spend time with children. Gend Soc. 2006; 20(2):25981.

27. Turner SP, West KP. A Qualitative Comparison of Women's Leadership Programs at Local and National Levels. J Dent Educ. 2006; 70(11):41-6.

28. Casadevall A. Achieving Speaker Gender Equity at the American Society for Microbiology General Meeting. MBio. 2015; 6(4):e01146-15.

\footnotetext{
Received on 09/23/2020

Approved on 07/21/2021

Conflict of interests: non-existent

Financial support: non-existent
} 